\title{
Aortic root surgery in Marfan syndrome: Comparison of aortic valve-sparing reimplantation versus composite grafting
}

\author{
Matthias Karck, MD \\ Klaus Kallenbach, MD \\ Christian Hagl, MD \\ Christine Rhein, MD \\ Rainer Leyh, MD \\ Axel Haverich, MD
}

From the Department of Thoracic and Car-
diovascular Surgery, Hannover Medical
School, Hannover, Germany.

Read at the Eighty-third Annual Meeting of The American Association for Thoracic Surgery, Boston, Mass, May 4-7, 2003.

Received for publication May 3, 2003; revisions accepted July 15, 2003; accepted for publication July 30, 2003.

Address for reprints: Matthias Karck, MD, Department of Thoracic and Cardiovascular Surgery, Hannover Medical School, 30623 Hannover, Germany (E-mail: Karck@thg.mh-hannover.de).

J Thorac Cardiovasc Surg 2004;127:391-8 $0022-5223 / \$ 30.00$

Copyright $\odot 2004$ by The American Association for Thoracic Surgery

doi:10.1016/j.jtcvs.2003.07.049
Objective: The objective of this study was to compare the results of aortic valvesparing reimplantation and aortic root replacement with mechanical valve conduits in patients with Marfan syndrome undergoing operation for aortic root aneurysms.

Patients and Methods: Between March 1979 and April 2002, 119 patients with clinical evidence of Marfan syndrome underwent composite graft replacement with mechanical valve conduits $(\mathrm{n}=74)$ or aortic valve-sparing reimplantation according to David $(\mathrm{n}=45)$. The underlying causes were aortic dissection type A (43 patients) and aneurysms (76 patients).

Results: Patients undergoing aortic valve reimplantation were younger compared with patients undergoing composite grafting ( 28 vs 35 years, $P=.002)$ and had longer intraoperative aortic crossclamp times $(125$ vs 78 minutes, $P<.0001)$ and extracorporeal circulation times (162 vs 124 minutes, $P<.0001$ ). Early postoperative mortality was $6.8 \%(\mathrm{n}=5)$ in patients undergoing composite grafting and $0 \%$ in patients undergoing aortic valve reimplantation $(P=.15)$. Mean follow-up was 30 months for patients undergoing aortic valve reimplantation and 114 months for patients undergoing composite grafting. Freedom from reoperation and death after 5 years postoperatively was $92 \%$ and $89 \%$ in patients undergoing composite grafting and $84 \%$ and $96 \%$ in patients undergoing aortic valve reimplantation $(P=.31 ; P=$ $.54)$, respectively. Thromboembolic complications or late postoperative bleeding occurred in 17 patients undergoing composite grafting, and an early postoperative event occurred in 1 patient undergoing aortic valve reimplantation.

Conclusions: The results of aortic valve reimplantation and composite grafting of the aortic valve and ascending aorta with mechanical valve conduits are similar with regard to early and mid-term postoperative mortality and to the incidence of late reoperations in patients with Marfan syndrome. The low risk of thromboembolic or bleeding complications favors aortic valve reimplantation in these patients.

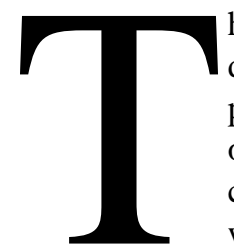

he life expectancy of patients with Marfan syndrome has increased dramatically in the last 30 years. ${ }^{1,2}$ The introduction of the Bentall procedure and its variants into clinical practice had a major impact on this positive development. ${ }^{3}$ Today, implantation of a valved conduit for aortic root replacement is the gold standard for patients with Marfan syndrome presenting with aneurysms of the aortic root. ${ }^{4}$ Although early and late postoperative outcomes of this procedure have been excellent, a significant proportion of patients with mechanical valve substitutes experience complications related to long-term anticoagulation with phenprocoumon. ${ }^{5}$ This 
TABLE 1. Preoperative characteristics of the patients who underwent the David operation or root replacement*

\begin{tabular}{lccc}
\hline & $\begin{array}{c}\text { David } \\
\text { operation }\end{array}$ & $\begin{array}{c}\text { Root } \\
\text { replacement }\end{array}$ & $\boldsymbol{P}$ value \\
\hline Number of patients & 45 & 74 & \\
Mean age (y) (mean \pm SD) & $28 \pm 12$ & $35 \pm 11$ & .002 \\
Sex & & & \\
$\quad$ Male & $29(64)$ & $49(66)$ & \\
$\quad$ Female & $16(36)$ & $25(34)$ & \\
Aneurysm & $41(91)$ & $35(47)$ & $<.0001$ \\
Type A aortic dissection & $3(7)$ & $17(23)$ & \\
$\quad$ Acute & $1(2)$ & $22(30)$ & \\
$\quad$ Chronic & $1(2)$ & $3(4)$ & \\
Associated pathology & $1(2)$ & 0 & \\
$\quad$ Bicuspid aortic valve & & \\
$\quad$ Coronary artery disease & $1(18)$ & $5(7)$ & \\
$\quad$ Mitral insufficiency & $8(1)$ & .013 \\
Previous cardiac surgery & 0 & $9(12)$ & \\
\hline
\end{tabular}

*Percentages are shown in parentheses.

TABLE 2. Operative data and additional procedures*

\begin{tabular}{|c|c|c|c|}
\hline & $\begin{array}{c}\text { David } \\
\text { operation } \\
\text { (n = 45) }\end{array}$ & $\begin{array}{c}\text { Root } \\
\text { replacement } \\
(\mathrm{n}=74)\end{array}$ & $P$ value \\
\hline Extracorporeal circulation time & $162 \pm 34$ & $124 \pm 45$ & $<.0001$ \\
\hline Aortic crossclamp time & $125 \pm 29$ & $78 \pm 26$ & $<.0001$ \\
\hline \multicolumn{4}{|l|}{ Additional procedures } \\
\hline Mitral valve repair & $8(18)$ & 0 & $<.0001$ \\
\hline Mitral valve replacement & 0 & $5(7)$ & .15 \\
\hline Proximal aortic arch replacement & $4(9)$ & $15(20)$ & .12 \\
\hline Total aortic arch replacement & 0 & $4(5)$ & .29 \\
\hline Coronary artery bypass & $1(2)$ & $4(5)$ & .64 \\
\hline ASD closure & $1(2)$ & 0 & .05 \\
\hline Funnel chest reconstruction & $2(4)$ & $1(1)$ & .55 \\
\hline
\end{tabular}

$A S D$, Atrial septal defect.

*Percentages are shown in parentheses.

fact and the generally young age of patients with Marfan syndrome undergoing surgery of the aortic root render biologic or even valve-sparing operative concepts attractive. However, there is a reluctance among surgeons with regard to preservation of the aortic valve in patients with Marfan syndrome because leaflets carrying a structural fibrillin-1 defect may not be stable enough for a long time, regardless of the type of valve reconstruction. ${ }^{6}$

On the other hand, there is increasing evidence that valve-sparing operations, such as the aortic root remodeling technique according to Yacoub or the reimplantation technique according to David, can be applied with good functional long-term results in patients with Marfan syndrome too. $^{7-9}$ This observation and the surprisingly long freedom from valve failure of up to 29 years that has been reported after 4 valve-sparing aortic root operations by Senning are good reasons to contest the restraints in this regard. ${ }^{4}$
Since 1993, we have used the aortic valve reimplantation technique according to David and have expanded the indications for this operation from acquired root pathologies to patients with Marfan syndrome with aneurysms of the aortic root. ${ }^{10}$ This report summarizes our experience with the reimplantation technique in 45 patients with Marfan syndrome in comparison with a nonmatched cohort of patients with Marfan syndrome who underwent aortic root replacement with mechanical valve conduits.

\section{Materials and Methods}

From March 1979 to April 2002, 132 patients with Marfan syndrome according to the Gent criteria underwent operation on the aortic root. ${ }^{11}$ Thirteen patients underwent aortic root replacement with a bioconduit (5 patients), resuspension of 1 or more aortic valve commissures and ascending aortic replacement (5 patients), aortic root reconstruction with gelatin resorcin formaldehyde glue and ascending aortic replacement (2 patients), or aortic root remodeling according to Yacoub (1 patient). In the other 119 patients, 45 underwent aortic valve reimplantation according to the method described by David and 74 underwent aortic root replacement with a mechanical valve conduit. ${ }^{3,8}$ Patients from the latter 2 cohorts form the basis of the subsequent analysis. The mean age of patients was 32 years (range 8-67 years). Operative procedures were performed electively in 99 cases. In 20 cases, however, patients had to undergo emergency surgery for acute aortic dissection type A. In most patients with Marfan syndrome undergoing operations between 1979 and 1993, aortic root replacement was performed with a composite graft of the aortic valve and ascending aorta. In 1993, aortic valve reimplantation was introduced in our institution. Since then, the number of patients undergoing this kind of valve-sparing operation has increased, whereas fewer and fewer patients have undergone combined replacement of the ascending aorta and aortic valve.

Table 1 summarizes the preoperative characteristics of patients who underwent aortic valve reimplantation or aortic root replacement with a mechanical valve conduit. Table 2 shows the operative data. Patients were followed up at annual intervals. Doppler echocardiography was performed in patients with aortic valve reimplantation. In addition, all patients with aortic dissection or subcritical aortic dilatation were reinvestigated serially by computed tomography. The mean follow-up was $30 \pm 27$ months (1-95 months) for patients who underwent aortic valve reimplantation and $114 \pm 63$ months (2-249 months) for patients who underwent composite graft replacement of the aortic valve and ascending aorta. None of these patients were lost to follow-up. Infectious, thromboembolic, and bleeding complications were recorded as recommended by the guidelines of the American Association for Thoracic Surgery and Society of Thoracic Surgeons. ${ }^{12}$

\section{Statistical Analysis}

Continuous variables are expressed as mean \pm SD. All data analyses were performed with SPSS 11.0 for Windows (SPSS, Chicago, Ill). Kaplan-Meier analysis was used for the evaluation of time-related variables, and the log-rank test was applied. The Mann-Whitney test was used for variables that were not normally 
distributed. The Student $t$ test for independent variables was used to test normally distributed variables between the composite and aortic valve reimplantation groups. Analysis of contingency tables was performed by Fisher's exact test or the $\chi^{2}$ test.

\section{Results}

\section{Hospital Mortality and Early and Late Postoperative Morbidity}

Five patients $(6.8 \%)$ died in hospital after aortic root replacement, whereas no patients died early after aortic valve reimplantation. Of these fatalities, the causes were acute type A aortic dissection in 2 patients, aneurysms in 2 patients, and chronic type A aortic dissection in 1 patient. Three patients died of low cardiac output after double reexploration of the mediastinum for bleeding. The other causes of early death were sepsis in 1 patient and stroke in 1 patient who underwent additional subtotal replacement of the aortic arch.

Altogether, 10 patients required reexploration of the mediastinum for bleeding ( 2 in the valve reimplantation group and 8 in the root replacement group).

There was no perioperative stroke, myocardial infarction, or infection in the reimplantation group. In the root replacement group, 2 patients had nonfatal strokes, 2 patients had reversible ischemic neurologic deficits, and 1 patient had a transient ischemic attack. None of these patients underwent additional mitral valve surgery. The anticoagulant status reported closest to the respective events ranged between 2.5 and 3.5 international normalized ratio in all patients.

The length of hospital stay was $15 \pm 9$ days in the reimplantation cohort and $20 \pm 18$ days in the aortic root replacement cohort $(P=.08)$.

There were 12 patients who had bleeding events in the root replacement group during further follow-up (3 with intracerebral bleeding, 3 with retinal bleeding, 3 with gastrointestinal bleeding, and 3 with severe epistaxis). No such episodes were reported in the reimplantation group.

Altogether, there were 17 of 69 survivors (24\%) in the root replacement group with a mechanical valve substitute who experienced bleeding episodes or thromboembolic events during their follow-up. In the reimplantation group, however, only 1 patient had a transient ischemic attack early postoperatively.

\section{Reoperations and Late Results}

Reoperation on the aortic valve was performed in 4 patients (9\%) after valve reimplantation. Technical problems during primary repair caused severe aortic valve incompetence 20 days postoperatively in 1 patient. Progressive aortic insufficiency (AI) during the first postoperative year occurred in 2 patients. At reoperation, cusp prolapse as the result of inadequate technique at the primary repair was identified as the cause of valve failure. Both patients demonstrated less than optimal cusp coaptation with aortic regurgitation greater than grade 1 in the early postoperative period. One patient received a prophylactic aortic valve replacement for AI grade II during aortic arch replacement 41 months after the primary repair. Preoperative echocardiography had revealed mild cusp prolapse beyond the inferior edge of the vascular graft. In all patients, valve replacement was performed within the Dacron prosthesis using mechanical prostheses. All patients recovered promptly from the second operation.

Seven patients $(9 \%)$ underwent cardiac reoperations after root replacement; indications were related to the composite graft in 6 of these patients. Two patients had prosthetic valve endocarditis. Other indications were persistent perfusion of the perigraft space in 1 patient, malfunction of the prosthetic heart valve in 1 patient, perforation near a coronary reimplantation site in 1 patient, and a relevant subprosthetic ventricular septal defect in 1 patient. One patient underwent heart transplantation for progressive cardiomyopathy late after root replacement. Two of the 7 patients in this subcohort died early postoperatively. Both patients underwent reoperation for prosthetic valve endocarditis. In 1 of these patients, the conduit was replaced by another composite graft, whereas the other patient underwent partial replacement of the ascending aortic prosthesis together with direct closure of a paravalvular leak. The former patient died as a sequel of early postoperative resuscitation and subsequent stroke, and the latter patient died of septic complications 10 days postoperatively. The other 5 patients are alive.

Figure 1 shows freedom from reoperation in both groups of patients; at 5 years it was $84 \% \pm 8 \%$ for patients who underwent aortic valve reimplantation and $92 \% \pm 3 \%$ for patients who underwent aortic root replacement $(P=.31)$.

In the reimplantation group, 3 patients died late postoperatively. In 1 patient, the cause of death was rupture of the native downstream aorta 5 years after primary repair. The 2 other patients died 5 and 6 years postoperatively of unknown reasons, therefore according to the respective guidelines, cardiac reasons. ${ }^{12}$ One patient died 4 years after mechanical aortic valve replacement as a reoperation for valve reimplantation. The cause of death was therefore unrelated to valve failure after reimplantation.

Figure 2 shows the survival in both groups of patients. Survival at 5 years was $96 \% \pm 4 \%$ for patients who underwent aortic valve reimplantation and $89 \% \pm 4 \%$ for patients who underwent aortic root replacement $(P=.54)$.

Figure 3 summarizes the results from the preoperative, early postoperative, and most recent Doppler echocardiographic study in patients who underwent aortic valve reimplantation. At the last visit, 23 patients showed no AI, 13 patients showed trivial AI, and 1 patient showed moderate 


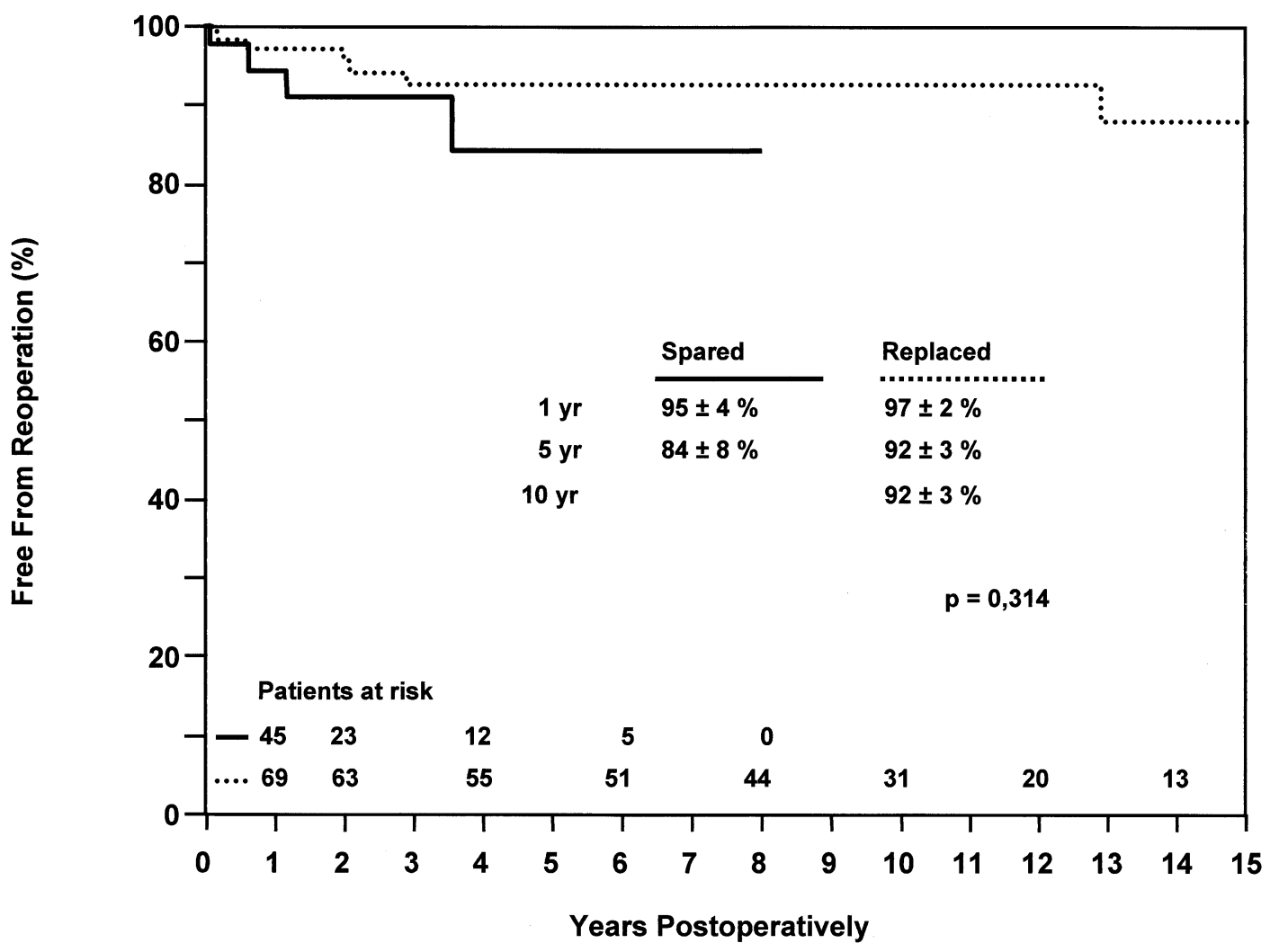

Figure 1. Freedom from reoperation in patients with Marfan syndrome who underwent aortic valve-sparing surgery by valve reimplantation according to David or root replacement by mechanical valved conduit.

to severe AI, who is presently not willing to undergo reoperation because of the lack of symptoms.

After aortic root replacement, 23 of the 69 surviving patients (33\%) underwent 1 or more separate reoperations at the downstream aorta for progressive dilatation or rupture. Among these 23 patients, 4 died early after emergency reoperations that were performed for imminent free rupture or acute malperfusion. One patient in this subcohort died 10 years after descending aortic replacement for unknown reason.

After aortic valve reimplantation, 3 of the 45 surviving patients $(6 \%)$ underwent downstream aortic reoperations. The indications were dilatation of a chronically dissected aortic arch, dilatation of a nondissected arch, and a secondary subacute type B aortic dissection. All patients who underwent reoperation were alive at the end of follow-up.

\section{Discussion}

There is an ongoing skepticism whether aortic valve-sparing procedures in patients with Marfan syndrome are justified in view of the proven microfibrillar abnormality within the aortic valve leaflets. ${ }^{6}$ Ten to 15 years ago, we and others put aside these concerns and decided to apply new and promising aortic valve-preserving concepts not only to patients with acquired diseases of the aortic root but also to patients with Marfan syndrome. ${ }^{7,8,10,13-15}$ We reviewed 45 patients meeting the Gent criteria of this disorder who underwent the classic David procedure for aneurysms of the aortic root at a mean follow-up of 30 months (range 1-94 months). Three results emerged from our study comparing our experience with this operation with the respective gold standard of composite grafting of the aortic valve and ascending aorta: (1) Hospital mortality, mid-term survival, and incidence of reoperation are comparable among patients undergoing operation with either of the 2 procedures. (2) No late thromboembolic and bleeding complications were observed in patients with aortic valve reimplantation (unlike patients with mechanical aortic valves). (3) Once initial repair was satisfactory, no late deterioration of valve function was observed after aortic valve reimplantation. Therefore, we conclude that aortic valve reimplantation according to David is favorable for patients with Marfan syndrome when compared with root replacement: Long-term anticoagulation is not required, and the reimplanted valves have performed well during the follow-up period that has accumulated so far.

According to a multicenter review by Gott and colleagues, ${ }^{4}$ elective repair of the aortic root in patients with Marfan syndrome carries a perioperative mortality risk of 


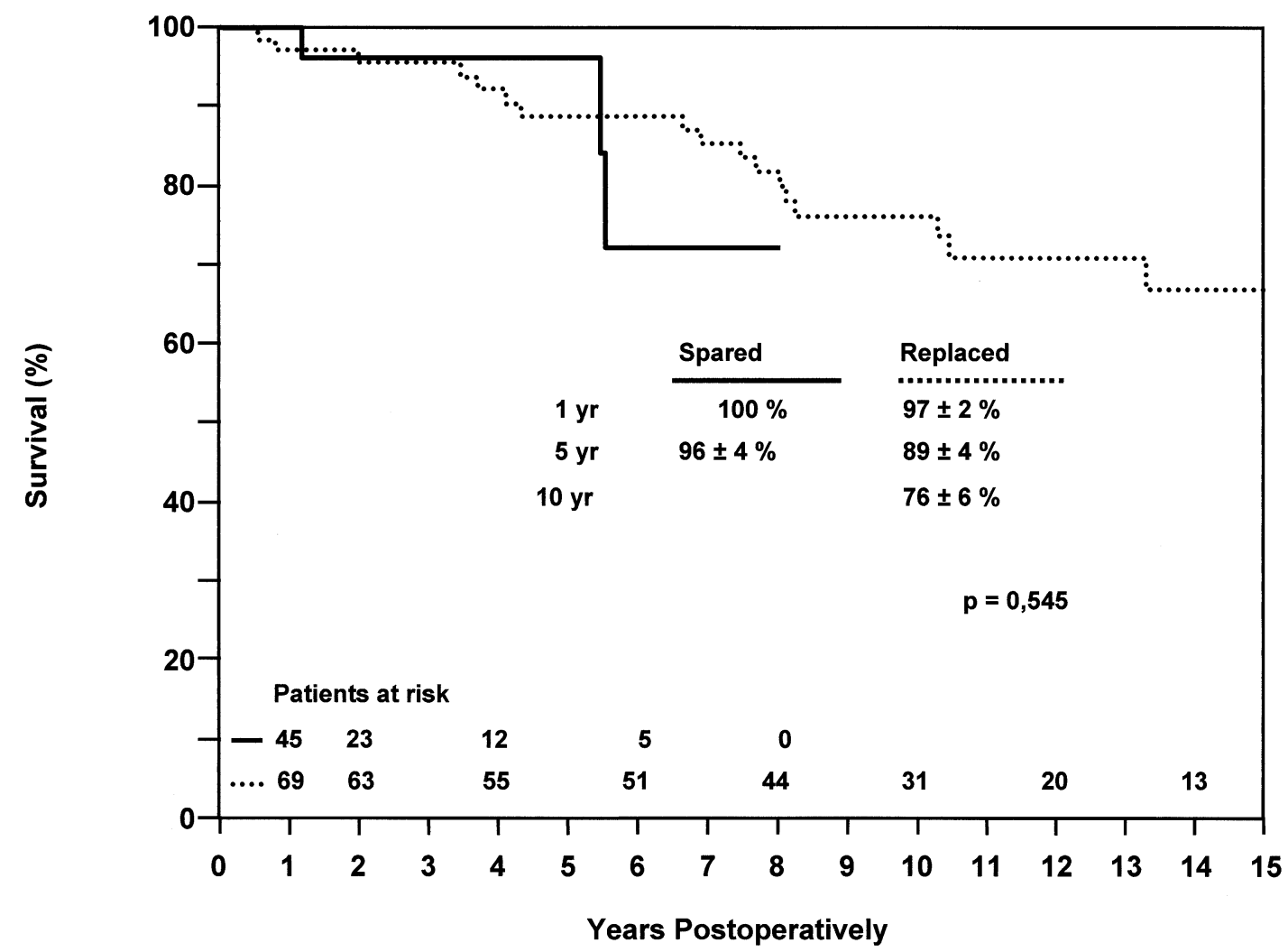

Figure 2. Survival of patients with Marfan syndrome who underwent aortic valve-sparing surgery by valve reimplantation according to David or root replacement by mechanical valved conduit.

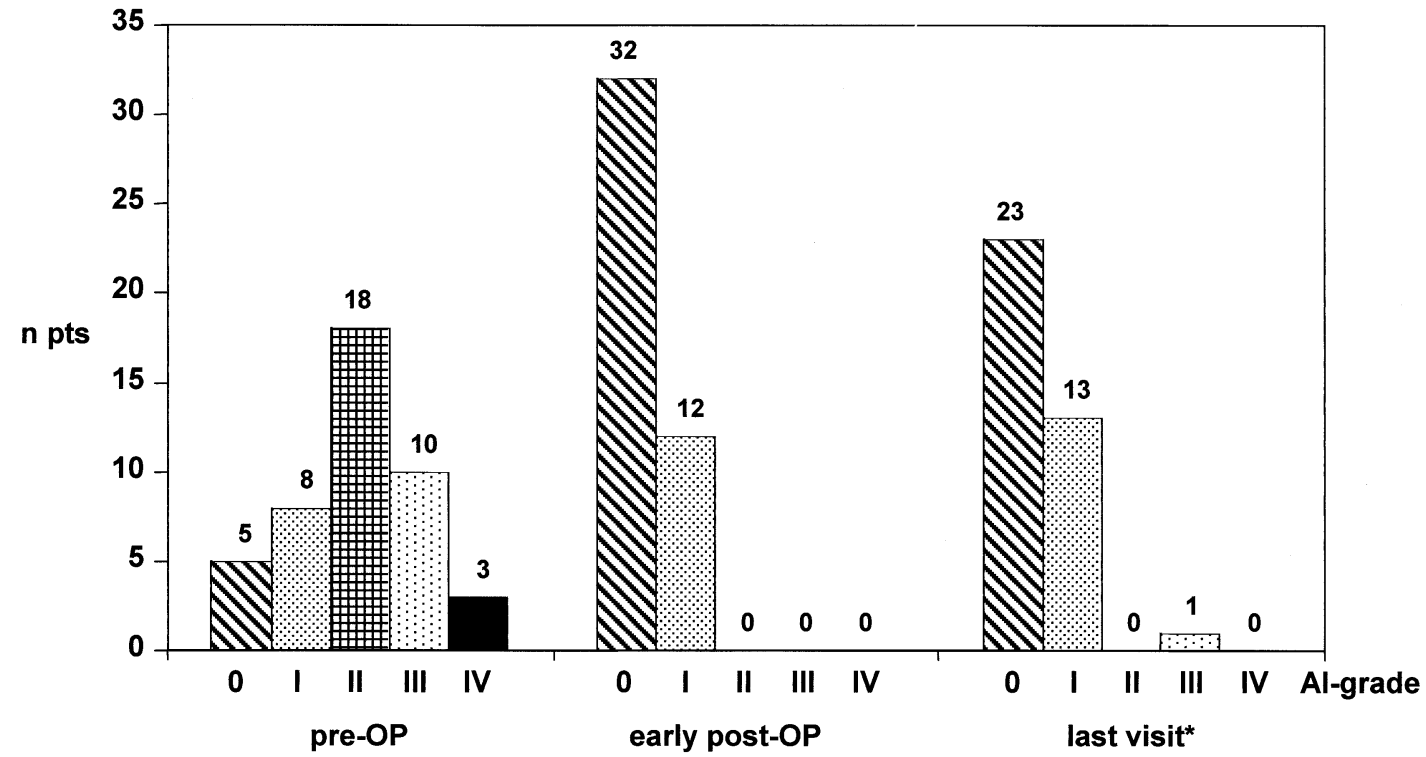

Figure 3. Grade of Al preoperatively, early postoperatively, and at last visit in patients with Marfan syndrome undergoing aortic valve-sparing surgery by valve reimplantation according to David. Absolute numbers of patients are given (n pts). Al, Aortic insufficiency. 
$1.5 \%$. The cumulative survival in that collective series was $85 \%$ at 5 years. These results were obtained because aortic root replacement by composite grafting of the aortic valve and ascending aorta has proven to be a straightforward and safe procedure. ${ }^{16}$

The zero early postoperative mortality we obtained with the David procedure can well compete in this regard even though the aortic crossclamp and extracorporeal circulation times were longer when compared with composite grafting. This result is in accordance with the early mortality rates for elective patients reported by David's group and the early results of the remodeling procedure according to Yacoub., ${ }^{7,9}$

Survival and mid-term postoperative outcome with this technique have been satisfactory so far, with 3 patients who died of reasons that were not attributable to valve reimplantation. The cumulative survival measures $96 \%$ at 5 years, which is comparative to results of root replacement and other series of patients with valve-preserving procedures. ${ }^{7,9,16}$

The most important adverse effect of valve repair remains valve failure. Early in our experience with valve reimplantation, 4 patients had to undergo reoperation for technical reasons. A detailed analysis of the intraoperative echocardiographic findings in 3 of these patients indicated that resuspension of the commissures was too low, thereby leading to cusp prolapse. We thus believe that radical dissection of the aortic root and adequate height of resuspension of the commissures are important to avoid early valve failure. ${ }^{10}$ It remains to be determined to what extent the structural fibrillin-1 defect can affect the stability and durability of the cusps after valve reimplantation. So far, we have no evidence (from echocardiography during follow-up or direct inspection of explanted valves) that obvious degenerative changes in the cusps were possibly attributable to contact with the prosthetic vascular graft. In our opinion, both aspects together with the more radical support of the diseased aortic wall and the routine annular stabilization are good reasons to continue to use David and Feindel's ${ }^{8}$ original technique (David I operation) in patients with Marfan syndrome. This applies to patients with normal cusps, which are generally found in root aneurysms smaller than $55 \mathrm{~mm}$. Valves with dilated cusps and multiple stress fenestrations, as typically seen in larger root aneurysms, should be replaced. ${ }^{9}$ It is conceivable, however, that the lack of sinuses of Valsalva still predisposes to leaflet damage, which could unmask only during further follow-up. This concern has led to modifications of the classic David I operation (David IV or $\mathrm{V}$ ) and the clinical introduction of vascular prosthesis incorporating artificial sinuses of Valsalva. ${ }^{17-19}$

The 2 study groups (valve reimplantation and root replacement with a mechanical aortic valve prosthesis) had a number of different perioperative variables (Table 1). One of the reasons why patients who underwent valve-sparing operations were younger when compared with patients who received a conduit probably resides in the more recent tendency to operate on root aneurysms at smaller diameters $(4.5-5 \mathrm{~cm})$ than 20 years ago in patients with Marfan syndrome. During recent years, we have tried to preserve the aortic valve in acute aortic dissection type A too. We believe there are 2 reasons why the proportion of patients with nondissecting aneurysms was still larger in patients with preserved aortic valves than in patients with replaced valves when looking at the whole study period: (1) Increased alertness among physicians with regard to the possible complications of Marfan syndrome may have contributed to the fact that fewer patients with Marfan syndrome have presented with type A aortic dissection during recent years. This may explain why only 5 patients had to undergo operation for this diagnosis during the last 7 years of the study period when compared with the 38 patients during the first 16 years. (2) The David operation was introduced into our clinical practice only during the last 9 years of the approximately 23 -year study period. Therefore, the statistical impact of the small number of patients with aortic dissection type A who had the chance to undergo valve reimplantation is relatively small, even though this operation was performed in all 5 patients who underwent operations since 1995 except for 1 patient with severely damaged leaflets.

No redo cases are documented in the cohort with valve reimplantation, whereas $12 \%$ of patients in the replacement group had undergone previous cardiac surgery. This finding probably reflects a surgical prevalence to accept the longer crossclamp times of aortic valve-preserving surgery in primary procedures rather than in redo interventions.

Another difference between the cohorts was the treatment of concomitant mitral valve insufficiency: There were no mitral valve replacements in the reimplantation group, whereas there were no mitral valve repairs in the root replacement group. With regard to the necessity of longterm anticoagulation, this finding reflects the efforts to repair not only the aortic valve but also the mitral valve whenever indicated.

In addition to these variables, the different length of follow-up in both cohorts certainly limits their statistical comparability. On the other hand, it is apparent that there were virtually no postoperative valve-related events in the reimplantation group. In contrast, $7.2 \%$ of the survivors of aortic root replacement with a mechanical aortic valve substitute have had thromboembolic complications, and 17.4\% of patients have had bleeding episodes. Although other causes for these complications are conceivable, these data well reflect the incidence of the adverse events that have been attributed to long-term phenprocoumon medication after mechanical valve replacement. ${ }^{5}$ Furthermore, the risk for dissection or dilatation of downstream aortic segments 
with the need for vascular reoperations renders patient management more difficult when long-term anticoagulation is necessary. Considering these aspects and in view of the presented data, we favor this valve-preserving operation in patients with Marfan syndrome, provided the valve cusps appear normal. However, only true long-term results will clarify its definite value in these patients.

We thank C. Abraham, $\mathrm{PhD}$, our consultant statistician, for biostatistical review of the study.

\section{References}

1. Murdock JI, Walker BA, Halpern BI, Kuzma JW, McKusick VA. Life expectancy and causes of death in the Marfan syndrome. $N$ Engl J Med. 1972;286:804-8.

2. Gott VL, Cameron D, Alejo DE, Greene PS, Shake JG, Caparrelli DJ, et al. Aortic root replacement in 271 Marfan patients: a 24-year experience. Ann Thorac Surg. 2002;73:438-43.

3. Bentall $\mathrm{H}$, DeBono A. A technique for complete replacement of the ascending aorta. Thorax. 1968;23:338-9.

4. Gott VL, Greene S, Alejo DE, Cameron DE, Naftel DC, Miller DC, et al. Replacement of the aortic root in patients with Marfan's syndrome. N Engl J Med. 1999;340:1307-13.

5. Horstkotte D, Schulte H, Biercks W, Strauter B. Unexpected findings concerning thromboembolic complications and anticoagulation after complete 10 year follow up of patients with St. Jude Medical prostheses. J Heart Valve Dis. 1993;2:291-301.

6. Fleischer KH, Nousari HC, Anhalt GH, Stone CD, Laschinger JC. Immunohistochemical abnormalities of fibrillin in cardiovascular tissues in Marfan's syndrome. Ann Thorac Surg. 1997;63:1012-7.

7. Birks EJ, Webb C, Child A, Radley-Smith R, Yacoub MH. Early and long-term results of valve-sparing operation for Marfan syndrome. Circulation. 1999;100(19 Suppl):II29-35.

8. David TE, Feindel CM. An aortic valve-sparing operation for patients with aortic incompetence and aneurysm of the ascending aorta. $J$ Thorac Cardiovasc Surg. 1992;103:617-22.

9. Tambeur L, David TE, Unger M, Armstrong S, Ivanov J, Webb G. Results of surgery for aortic root aneurysm in patients with the Marfan syndrome. Eur J Cardiothorac Surg. 2000;17:415-9.

10. Harringer W, Pethig K, Hagl C, Meyer GP, Haverich A. Ascending aortic replacement with aortic valve reimplantation. Circulation. 1999; 100(19 Suppl):II24-8.

11. De Paepe A, Deveeux RB, Dietz HC, Hennekam RC, Pyeritz RE. Revised diagnostic criteria for the Marfan syndrome. Am J Med Genet. 1996;62:417-26.

12. Edmunds LH, Clark RE, Cohn LH, Grunkemeier GL, Miller DC, Weisel RD. Guidelines for reporting morbidity and mortality after cardiac valvular operations. J Thorac Cardiovasc Surg. 1996;112:70811.

13. Kallenbach K, Hagl C, Walles T, Leyh RG, Pethig K, Haverich A, et al. Results in valve-sparing aortic root reconstruction in 158 consecutive patients. Ann Thorac Surg. 2002;74:2026-33.

14. Kallenbach K, Karck M, Leyh RG, Hagl C, Walles T, Haringer W, et al. Valve sparing aortic root reconstruction in patients with significant aortic insufficiency. Ann Thorac Surg. 2002;74:S1765-8.

15. Kallenbach K, Pethig K, Schwarz M, Milz A, Haverich A, Harringer W. Valve sparing aortic root reconstruction versus composite replacement-perioperative course and early complications. Eur J Cardiothorac Surg. 2001;20:77-81.

16. Mingke D, Dressler C, Stone CD, Borst HG. Composite graft replacement of the aortic root in 335 patients with aneurysm or dissection. Thorac Cardiovasc Surg. 1998;46:12-9.

17. Miller DC. Valve-sparing aortic root replacement in patients with the Marfan syndrome. J Thorac Cardiovasc Surg. 2003;125:773-8.

18. DeOliveira NC, David TE, Ivanov J, Armstrong S, Eriksson MJ, Rakowski $\mathrm{H}$, et al. Results of surgery for aortic root aneurysm in patients with Marfan syndrome. J Thorac Cardiovasc Surg. 2003;125: 789-96.
19. DePaulis R, De Matteis GM, Nardi P, Scaffa R, Buratta M, Chiariello L. Opening and closing characteristics of the aortic valve after valve sparing procedures using a new aortic root conduit. Ann Thorac Surg. 2001;72:487-94.

\section{Discussion}

Dr Tirone E. David (Toronto, Ontario, Canada). It pleases me to know that Professor Borst introduced this operation in Hannover almost a decade ago and that you and your associates continue to perform it. I think it is a good operation for patients with Marfan syndrome. Having said that, considering the results that you have had, I would be reluctant to offer it to new patients. The patients who had replacement of the aortic root were older and sicker, had more aortic dissections, and had many more transverse aortic arch replacements, and yet at 5 years the survival was the same. The risk of reoperation in the valve-sparing group was higher than in the aortic root replacement group. My explanation for that is not because valve sparing is a bad operation, but rather because of its learning curve.

I have been performing this operation for some 15 years, and I still find it a difficult operation to teach-not the technical aspects of reimplanting the aortic valve into a tube but the operative judgment of whether to save or replace an aortic valve and to select the size of the graft for the reimplantation. How did you choose the size of the graft? What guidelines do you use in the operating room to pick a graft of 34 or $26 \mathrm{~mm}$ ?

Second, what do you do for the elongated cusps? Invariably if a patient has an aortic root aneurysm, the cusps won't be entirely normal. Thus, the principles of functional anatomy of the aortic valve are not easily applicable in patients with aortic root aneurysm. In other words, it has been my experience that the cusps are often elongated, particularly the noncoronary cusp. If you take a graft of a given size, the cusps may prolapse at the end of the operation. Do you repair the cusps? Do you shorten them?

Finally, isn't the creation of the neo-aortic sinus important for the function of the aortic valve? There is an increased amount of evidence suggesting that the velocity of closure of the aortic cusps decreases when neo-aortic sinuses are created.

Dr Karck. I am aware that you have developed a specific formula to calculate the optimum size of the tube graft to use. This is a difficult formula for us, and reviewing our data, it turns out that the vast majority of patients, including patients with Marfan syndrome, received a $28-\mathrm{mm}$ prosthesis if male and a $26-\mathrm{mm}$ prosthesis if female. The results we obtained, even though I understand the theoretical point, support the selection of these tube graft sizes. Few patients with exceptionally wide annuli had tube grafts with wider diameters.

Dr David. I'm sorry, you don't have a criterion for selecting 26 or 28 ? It is random?

Dr Karck. No, we measure, but this resulted in 28-mm or 26-mm tube grafts for the majority of patients with Marfan syndrome.

With regard to cusp elongation, we carefully assess the aortic valve, particularly in the area of the commissures. If there are stress fenestrations, we replace this valve instead of trying to reconstruct it. Commonly we see these stress fenestrations in patients who have a very wide annulus. I missed the third question.

Dr David. The need to create neo-aortic sinuses as opposed to a straight tube. 
Dr Karck. There are some data on the importance of sinus function. From the work of Dr Leyh, who analyzed this aspect between the Yacoub operation and the David operation comparatively, we learned that the lack of sinus function has not affected the clinical outcome so far. In other words, with the follow-up we have accumulated so far, we do not see deterioration of the cusps or any disadvantages that may be attributable to the loss of sinus function.

Dr Gerald M. Lawrie (Houston, Tex). I enjoyed this beautifully presented article. I wanted to make a brief comment about the long-term natural history of this disease. Ten years ago, we had the opportunity to publish a report on a series of 277 patients who underwent operations at Baylor in the 1960s and 1970s before composite grafts were prevalent (Lawrie GM, Earle N, DeBakey ME. Long-term fate of the aortic root and aortic valve after ascending aneurysm surgery. Ann Surg. 1993;217:711-20). We ended up with a series of patients with simple tube grafts, with or without a separate prosthetic aortic valve replacement. As a result, we had 277 aortic roots and 118 native aortic valves that we were able to follow for up to 40 years.

What we found was that simple tube graft replacement in the patients without Marfan syndrome was a very reliable operation; $96 \%$ of the roots and their native valves came through 10 years without any problem. On the other hand, the patients with Marfan syndrome did not do so well. These patients had an $86 \%$ freedom from reoperation for their root disease and only a $75 \%$ survival of their Marfan valves, which were originally competent. This $25 \%$ incidence of $\mathrm{AI}$ at 10 years is very similar to what Dr Tirone David published last month for his patients undergoing valve-sparing surgery (de Oliveira NC, David TE, Ivanov J, Armstrong S, Eriksson MJ, Rakowski H, et al. Results of surgery for aortic root aneurysm in patients with Marfan syndrome. $J$ Thorac Cardiovasc Surg. 2003;125:789-96).

Although this isn't a direct parallel to your article, we did note several points that would bear on your presentation. The first is that most of these problems emerged in the 5- to 10-year time interval. We had very few problems, almost no problems at all, in the 0 - to 5-year interval. So I would continue to be cautious about the wide application of this concept in Marfan syndrome. This is a real problem. Again, 40 of 277 patients had Marfan syndrome, and $50 \%$ of the reoperations in the entire group were in those 40 patients.

I am glad to see you did pay attention to the incidence of recurrent AI in great detail. I think we need to get back somewhat parallel to the mitral repair situation in which we report the success of our reconstructions according to the presence or absence of AI rather than reoperation rates. AI is serious but sometimes well tolerated for long periods of time, and I think we need to focus on whether there is a competent valve or not.

Dr Karck. I agree. We have to wait until we have accumulated much longer follow-up times. It is possible that beyond 5 years of follow-up, complications will occur. So far, however, the results are quite encouraging. Therefore, we will continue to offer this operation to patients with Marfan syndrome too.

\section{Bound volumes available to subscribers}

Bound volumes of The Journal of Thoracic and Cardiovascular Surgery are available to subscribers (only) for the 2004 issues from the Publisher, at a cost of $\$ 134.00$ for domestic, $\$ 165.85$ for Canadian, and $\$ 155.00$ for international subscribers for Vol 127 (January-June) and Vol 128 (July-December). Shipping charges are included. Each bound volume contains a subject and author index and all advertising is removed. The binding is durable buckram with the Journal name, volume number, and year stamped in gold on the spine. Payment must accompany all orders. Contact Elsevier Inc., Subscription Customer Service, 6277 Sea Harbor Dr, Orlando, FL 32887, USA; phone 800-654-2452 or 407-345-4000.

Subscriptions must be in force to qualify. Bound volumes are not available in place of a regular Journal subscription. 